\title{
THE USE OF A WIKI TO FACILITATE COLLABORATIVE LEARNING IN A SOUTH AFRICAN PHYSIOTHERAPY DEPARTMENT
}

\begin{abstract}
The dominant form of teaching in higher education remains the lecture, even though evidence suggests that it alone is inadequate to facilitate the development of the higher order thinking skills required in clinical practice. The use of wikis may have a role to play in facilitating collaborative learning practices that are important for professional development. This descriptive survey evaluated the use of a wiki for a collaborative learning activity within small groups of undergraduate physiotherapy students in a South African university. Students participated in a wiki-based assignment and were then surveyed using open- and closed-ended questions to determine their perceptions and experiences of the process. The results indicate that although a wiki can be used to develop relevant content, there were significant challenges in its implementation. These included a poor understanding by students of how to work effectively in groups, a lack of physical and epistemological access to the internet, and the need for adequate preparation and support. Some features of the wiki were found to have an impact on the quality of the work produced, including the use of Discussion pages, peer review, and the public nature of the wiki. The conclusion is that wikis may have a role to play in collaborative groupwork, but that that students need to be adequately prepared and supported throughout the process.
\end{abstract}

KEY WORDS: COLLABORATION, EDUCATION, GROUPWORK, PHYSIOTHERAPY, SOUTH AFRICA, WIKI.

\section{INTRODUCTION}

Despite evidence that learning is social and a property of interaction between people (Vygotsky 1978; Wenger 1998), the dominant form of teaching today is the traditional lecture, in which knowledge is supposedly "transferred" from the teacher to the student. While lectures can be effective when used in the right context, there is growing evidence to suggest that they may not be the best way to learn, especially if they are poorly implemented (McGarr 2009). Learning is contextual and most effective when the development of knowledge is a product of mutual and creative dialogue that is influenced by the context and culture in which it occurs. However, activities that promote dialogue, collaboration and engagement are often difficult to incorporate into traditional lectures (Magennis and Farrell, 2005). A teaching approach that incorporates opportunities for collaboration and engagement may enhance the teaching and learning process (Sharma and Hannafin, 2005; Magennis and Farrell, 2005).

Social constructivism is a useful lens through which to view collaborative learning, as it emphasises the active construction of knowledge through personally meaningful learning activities that are social in nature. In addition, the approach stresses that multiple perspectives are both valued and necessary, meaning that learning in groups adds value to the personal construction of knowledge (Partlow and Gibbs 2003).

Social constructivist teaching principles may be best applied through the integration of online social spaces within the traditional curriculum. One online tool that is being used increasingly often in healthcare education, is the wiki (Boulos, Maramba and Wheeler, 2006). A wiki is a website that allows the creation of web pages by one or many users who can add, edit and delete online con- tent without requiring any knowledge of HTML. ${ }^{1}$ Wikis have no pre-determined format, and can therefore be thought of as flexible spatial structures that can be expanded indefinitely, making them useful platforms for knowledge management. Wikis also contain features that make them well-suited to collaborative work, such as Discussion pages and versioning capabilities that allow one to track a document's evolution over time (Duffy and Bruns, 2006). At their core, wikis are less about technology, and more about collaboration around shared objectives within groups (Lundin, 2008).

\footnotetext{
Corresponding Author:

M. Rowe

Department of Physiotherapy

University of the Western Cape

Private Bag X17

Bellville

7530

South Africa

E-mail: mrowe@uwc.ac.za
} 
There is therefore evidence to consider the use of wikis as part of a teaching and learning approach that makes use of social constructivist principles. Together with the move towards integrating technology into curricula, the researcher felt that an understanding of students' experiences and perceptions around the use of technology within the curriculum was important before making decisions about larger curriculum changes in that direction. This survey therefore aimed to determine student perceptions of the use of a wiki as part of an assignment to develop content collaboratively in small groups. The objectives of the survey were to determine how students felt about using a wiki to collaboratively develop content as part of their module, to evaluate their perceptions of groupwork while using the wiki, and to determine the challenges of using a wiki in a South African university physiotherapy department.

\section{METHODS}

\section{Research Setting and Sample}

The survey took place in a university physiotherapy department in the Western Cape, South Africa. The sample included all final year physiotherapy students who were registered for the Applied Physiotherapy module during 2009 and consisted of 46 students. Prior to participating in this assignment, students had had regular group-based assignments as part of the course. However, none of these had ever included an online component as part of the assignment and all groupwork was done by students in the same physical space.

\section{Assignment design}

Historically the module was taught using a lecture format, with assignments being a variation of either individual evidencebased essays or a group-based presentation. For the purpose of this study, a wiki-based assignment was designed, guided by social constructivist principles. Students were required to gather information related to the assessment, treatment and management of common conditions in paediatric patients. An additional objective of the assignment was to develop certain generic graduate attributes, which include an ability to "... actively engage in the generation of... relevant knowledge", as well as being able to "...work in a productive team" (University of the Western Cape, 2009).

Students were randomly split into small groups of 6 members, with each group having to create pages within the wiki as part of their assignment. They were also required to review the work of other groups, using the Discussion feature of the wiki. This review process included giving advice for improvement of the assignment, as well as providing links to additional resources that would benefit the other groups. The use of a wiki-based assignment that was constructively aligned with the module learning outcomes and university Graduate Attribute policy was thus an appropriate method to collaboratively and critically engage with content and with each other (Biggs, 2003; Jones, 2007).

The wiki was created using Mediawiki, an open-source wiki-engine that is stable, secure and feature rich (Augar, Raitman and Zhou, 2004). The lecturer prepared the students by providing them with a slide presentation demonstrating a step-by-step version of the editing process, creating a video highlighting the features of the wiki, and giving them a handout explaining how to access and edit the wiki. A Help section was also created within the wiki, linking to additional information around formatting, embedding multimedia and referencing within the online platform.

\section{Research Design and Data analysis}

This descriptive survey made use of a self-developed, self-administered questionnaire that was distributed to all students following completion of the assignment. The questionnaire used open- and closed-ended questions to determine students' experiences and perceptions of using the wiki to work together in groups. Data were captured using OpenOffice.org Calc.

Responses to the closed-ended questions were analysed using frequencies and proportions. The open-ended responses were analysed in order to identify themes that emerged from the data, and analysis was conducted by two researchers until consensus was reached.

\section{Ethical considerations}

Since this study formed a peripheral part of a larger research project, ethical clearance had already been obtained (registration number: 09/8/16), and permission to conduct the survey was given by the head of the physiotherapy department. Students were provided with an information sheet giving the reason for the survey and informed that they were not obliged to participate and would not suffer any negative consequences should they choose not to. Confidentiality was assured by not gathering any personally identifiable information.

\section{RESULTS}

Forty six questionnaires were distributed to the students and 37 were returned, indicating a response rate of $80 \%$. Nineteen percent $(n=7)$ of respondents were male, and $81 \% \quad(n=30)$ were female. The age range for the 37 respondents was 21-33 years, with an average of 21 years. Sixty two percent $(n=23)$ of the class had never heard of wikis prior to the assignment and only one student reported having edited one, although every student had used Wikipedia as a resource.

Students reported mixed initial reactions to the assignment, although the overwhelming response was negative $(n=29,78 \%)$. The following example quotes are presented from students' responses to the question, "How did you feel when you were told about the wiki-based assignment?":

"Not very excited, because I am not interested in such technology"

"Stressed because I don't like working on the net"

" $A$ bit shocked cause we usually print out our assignments"

\section{Using the wiki to achieve the assign- ment outcomes}

Table 1 presents the students' perceptions of their achievement of the assignment objectives. 
Table 1: Students responses around the use of a wiki to achieve the assignment learning outcomes ( $N=37)$

\begin{tabular}{|c|c|c|c|c|c|}
\hline Statement & $\begin{array}{l}\text { Strongly } \\
\text { agree }\end{array}$ & Agree & Uncertain & Disagree & $\begin{array}{l}\text { Strongly } \\
\text { disagree }\end{array}$ \\
\hline $\begin{array}{l}\text { We produced an article that contributed towards my } \\
\text { understanding of our topic }\end{array}$ & $\begin{array}{l}7 \\
(19 \%)\end{array}$ & $\begin{array}{l}18 \\
(49 \%)\end{array}$ & $\begin{array}{l}7 \\
(19 \%)\end{array}$ & $\begin{array}{l}5 \\
(14 \%)\end{array}$ & 0 \\
\hline $\begin{array}{l}\text { We made a useful contribution to the body of } \\
\text { knowledge that may help others }\end{array}$ & $\begin{array}{l}5 \\
(14 \%)\end{array}$ & $\begin{array}{l}25 \\
(68 \%)\end{array}$ & $\begin{array}{l}6 \\
(16 \%)\end{array}$ & $\begin{array}{l}1 \\
(1 \%)\end{array}$ & 0 \\
\hline $\begin{array}{l}\text { Getting feedback and links to further resources helped } \\
\text { the group to produce a better quality article }\end{array}$ & $\begin{array}{l}5 \\
(14 \%)\end{array}$ & $\begin{array}{l}15 \\
(41 \%)\end{array}$ & $\begin{array}{l}13 \\
(35 \%)\end{array}$ & $\begin{array}{l}3 \\
(8 \%)\end{array}$ & $\begin{array}{l}1 \\
(3 \%)\end{array}$ \\
\hline $\begin{array}{l}\text { It helped me to understand the importance of progres- } \\
\text { sively improving a document through feedback and } \\
\text { further research }\end{array}$ & $\begin{array}{l}10 \\
(27 \%)\end{array}$ & $\begin{array}{l}25 \\
(68 \%)\end{array}$ & $\begin{array}{l}1 \\
(3 \%)\end{array}$ & 0 & $\begin{array}{l}1 \\
(3 \%)\end{array}$ \\
\hline It helped me to improve my academic writing skills & $\begin{array}{l}3 \\
(8 \%)\end{array}$ & $\begin{array}{l}17 \\
(46 \%)\end{array}$ & $\begin{array}{l}10 \\
(27 \%)\end{array}$ & $\begin{array}{l}6 \\
(16 \%)\end{array}$ & $\begin{array}{l}1 \\
(3 \%)\end{array}$ \\
\hline
\end{tabular}

Table 2: Respondents' perceptions on the use of a wiki to facilitate collaborative groupwork ( $\mathrm{N}=37$ )

\begin{tabular}{|c|c|c|c|c|c|}
\hline Statement & $\begin{array}{l}\text { Strongly } \\
\text { agree }\end{array}$ & Agree & Uncertain & Disagree & $\begin{array}{l}\text { Strongly } \\
\text { disagree }\end{array}$ \\
\hline $\begin{array}{l}\text { Using a wiki helped me to learn more about the topic } \\
\text { than if I had completed the assignment alone }\end{array}$ & $\begin{array}{c}3 \\
(8 \%)\end{array}$ & $\begin{array}{c}7 \\
(19 \%)\end{array}$ & $\begin{array}{c}7 \\
(19 \%)\end{array}$ & $\begin{array}{c}16 \\
(43 \%)\end{array}$ & $\begin{array}{c}4 \\
(11 \%)\end{array}$ \\
\hline $\begin{array}{l}\text { Using a wiki is a good way to work on group } \\
\text { assignments and projects }\end{array}$ & $\begin{array}{c}3 \\
(8 \%)\end{array}$ & $\begin{array}{c}8 \\
(22 \%)\end{array}$ & $\begin{array}{c}16 \\
(43 \%)\end{array}$ & $\begin{array}{c}6 \\
(16 \%)\end{array}$ & $\begin{array}{c}4 \\
(11 \%)\end{array}$ \\
\hline $\begin{array}{l}\text { Using a wiki encouraged me to work with the others } \\
\text { in my group }\end{array}$ & 0 & $\begin{array}{c}9 \\
(24 \%)\end{array}$ & $\begin{array}{c}7 \\
(19 \%)\end{array}$ & $\begin{array}{c}18 \\
(49 \%)\end{array}$ & $\begin{array}{c}3 \\
(8 \%)\end{array}$ \\
\hline $\begin{array}{l}\text { I feel more confident with groupwork after this } \\
\text { assignment }\end{array}$ & $\begin{array}{c}2 \\
(5 \%)\end{array}$ & $\begin{array}{c}6 \\
(16 \%)\end{array}$ & $\begin{array}{c}11 \\
(30 \%)\end{array}$ & $\begin{array}{c}15 \\
(41 \%)\end{array}$ & $\begin{array}{c}3 \\
(8 \%)\end{array}$ \\
\hline
\end{tabular}

\section{Challenges with group dynamics}

This section presents results around the use of the wiki to facilitate collaboration in groups. Most students did not believe that the wiki was a useful way for them to learn in groups. Table 2 presents their responses on their perceptions of the use of a wiki for the assignment.

However, not all students had poor experiences using the wiki. The following quotes suggest ways in which using a wiki could be useful:

"I think a wiki is useful to do group work, because the group is still able to work collaboratively even if meeting is not possible"

"It is if the members are not in the same geographical location. It also makes time an irrelevant factor" "...you can work from home in your own time and don't have to find a time when everyone can get together" Respondents who were not happy with their final assignments $(n=11)$ reported specific problems within their groups, which they believed had resulted in poorer work being produced. ${ }^{2}$ The following quotes provide some examples of this:

“...only 2 group members mainly contributed so it could have been better had the whole group contributed equally"

"Quality could have been much better but the fact that each person only paid attention to certain parts and no-one proof read the entire document was a problem"

"I felt that our article could have been of a higher quality if each member visited the site more often"
Even though the majority of students blamed low quality work on their peers, when asked to rate their group members' contributions on a scale of $0-10$, respondents gave other students the same score, on average, that they gave themselves (7 out of 10).

Poor communication within groups emerged as an important factor in respondents' dissatisfaction with using the wiki. However, few students used the Discussion feature to share ideas or otherwise collaborate during the assignment. The following quotes indicate some of the problems around students' communication:

"We never actually communicated"

"Did not really collaborate, just expanded on their content"

"No one really discussed how the work would be divided. Everyone did their own thing"

2 No correlations were done on student perceptions of the quality of work, and the marks that each group received. 
Three participants highlighted issues around trust within their particular groups, as can be seen in the following quotes:

"...if we can work with people WE

TRUST!!! I hate and do not feel safe working with people I don't know and who don't want to know me"

"...people would have to take responsibility to pull their own weight and we would have to trust them to do so" "I felt nervous working with people I do not talk or communicate to"

\section{Peer review aspect of the assignment}

Eighty one percent $(n=30)$ responded positively to the peer review component of the assignment, as highlighted by the following quotes:

"Insight and views from more people makes one think more..."

"I thought it was a learning curve because we could help each other understand things that we were clueless about"

"It was good and interesting to hear different view points. I felt challenged and excited by the arguments or agreements to my review"

During the peer review component of the assignment, students commented on the fact that plagiarism was identified as a problem, as highlighted by the following quotes:

"Controlling the quality, ensuring that the content of the assignment was referenced and not plagiarised"

"Trying to sort out the mess and plagiarism"

"People just cutting and pasting content, obvious plagiarism”

In response to the question, "How did you feel knowing your work was visible to the world?", $40 \%(n=15)$ were indifferent, $46 \%(n=17)$ were excited and proud, and $14 \%(n=5)$ were apprehensive or nervous. As a result of knowing that their work would be publicly visible, $57 \%(n=21)$ reported doing more research for this assignment than they would normally have done.

\section{Challenges when working with a wiki}

In addition to the problems with group- work that have already been highlighted, students reported issues around physical access to the internet, as well as a lack of preparation and support during the assignment.

\section{Access to the internet}

Lack of internet access featured prominently in students' responses to questions around the challenges they faced in completing the assignment. Almost half of the participants (48\%) accessed the internet from home, just over a quarter from campus $(27 \%), 15 \%$ from an internet café and 9\% from other locations e.g. a friend or family member's home. Students who did not have access to the internet at home felt that this impacted on their ability to contribute to the assignment, as can be see with the following quotes:

"...I don't have internet at home and it was difficult to go to the internet cafe'"

“...it's very stressful for those of us who have no internet at home. Often computer labs are full and sometimes you won't get a space to complete your assignment. Or the lab closes before I finish my work"

"Obscene amounts of money is spent to use internet cafes and traveling [sic] to campus"

\section{Inadequate preparation and support}

Fifty seven percent $(\mathrm{n}=21)$ of students reported that they felt that they were not adequately prepared to participate in the wiki prior to beginning the assignment, and thirteen $(35 \%)$ believed that the lecturer could have done more to prepare them. They suggested that a practical session prior to the assignment would have been useful.

\section{DISCUSSION}

The aim of this study was to determine students' perceptions of the use of a wiki to develop content collaboratively as part of an Applied Physiotherapy module. In addition, the study sought to evaluate their perceptions of groupwork while using the wiki, and to determine the challenges of using a wiki in a South African university physiotherapy department.

\section{Demographics}

These students had very little experience with wikis prior to participating in this assignment, with only one of them reporting having edited one. And, even though they fell into the age-delineated category known as the Net Generation, it was clear that their experiences of using a wiki contrasted with some claims that this cohort of students think and learn differently as a result of digital immersion (Prensky, 2001a). This highlights the fact that care must be taken when using literature to drive educational strategies that occur in different socio-cultural and historical contexts. We need to consider that not only do these ideas often reflect a North American and European bias, but that the concept of a Net Generation is in itself misleading. The implication that one's date of birth can predict their ability to participate in online spaces ignores the more salient factors such as regional or institutional infrastructure, diversity of the student body, previous educational experiences and socio-economic background (Czerniewiecz and Brown, 2005; Bennet, Maton and Kervin, 2008). We should therefore be wary of making assumptions about our students' abilities to participate in online environments like wikis.

\section{Challenges with group dynamics}

Most participants were uncertain or disagreed that wikis provided a useful environment for group assignments, or that it helped them to work with others in the group, or that it gave them confidence when working in groups. The respondents who reported that wikis were useful suggested that although they could facilitate collaborative work when participants were geographically separate, there was still a need to meet in person. The students who believed that they had produced a poorer article than they were capable of producing as individuals, highlighted several problems within the group, including inconsistency, differing levels of contribution (even though they gave other group members the same rating for contribution that they gave themselves), lack of structure and established roles within the group. For example, no group leader 
was selected and so the members fell back to working as individuals with no co-ordinated effort. This was supported by the fact that only $24 \%(n=9)$ of participants agreed that the wiki encouraged them to work with other group members. The presence of a leader within wikibased group assignments has been found to benefit the group in terms of better co-ordinating activities (Ramanau and Geng, 2009).

These respondents seemed unprepared to work in groups and in particular, struggled to engage with each other within the wiki. In addition, even though the lecturer provided some material to help students prepare for the assignment, the lack of a practical session almost certainly had implications for the disconnect in how they used and understood the wiki. The difficulty that the students experienced with groupwork highlights the fact that just because a wiki was used to facilitate collaborative groupwork, collaboration did not arise spontaneously. This confirms the need for consistent facilitation and online presence of a teacher throughout the learning activity (Garrison and Anderson, 2003).

Some group members highlighted a lack of trust impacting their willingness to work within the group. The establishment of roles by the group at the outset may have helped alleviate the lack of trust identified by some of the group members. The role of trust within groups has been found to impact willingness to participate and to share, while communication and face-to-face interaction over time are necessary in order to build trust (Gannon-leary and Fontainha, 2007). In addition, establishing a comfortable and social online space is necessary for cognitive development (Shea and Bidjerano, 2009), which may explain why students who struggled with trust issues within the group found it difficult to work effectively. As educators we must be cognisant of the fact that groupwork requires additional communication strategies and support, and even more so when social cues such as gesture, facial expression and body language, are missing in online communication (Stahl and Hesse, 2006).

\section{Peer review aspect of the assignment}

For many of the students, this was the first time that they were working transparently, in the sense that their work could be seen by their peers, their lecturer and the general public. Instead of creating a sense of fear as might be expected, halfof these students responded by working harder for this assignment than they normally would. There may be something to be said for introducing students to the notion of being publicly accountable for their work as students, just as they are accountable to the public for the work they do as professionals.

Many respondents agreed that drafting and feedback in the form of comments and links to additional resources were important factors in improving the quality of the work they produced. This may be a result of students seeing their work from others' perspectives (Game and Metcalfe, 2009), as well as the fact that peer review has been identified as a rewarding experience for students (Mak and Coniam, 2008). Even though peer review can be designed to be part of paper-based assignments, it would be difficult to implement on the same scale or with the same convenience.

Another advantage of the drafting and peer review process was the ease with which instances of plagiarism could be identified by the lecturer, and confirmed with a simple search. The lecturer then pointed out the copied text to the group via the Discussion feature of the wiki, along with a link to the original source, included additional resources explaining plagiarism, and suggestions on how to "clean up" the text. This approach made use of a "connect", rather than "challenge" model of discourse, which has been shown to help build relationships and trust in online environments (Trena, 2006).

\section{Challenges when working with a wiki}

Access to the internet was highlighted by respondents as being one of the main reasons that they could not participate in the assignment more frequently, with $52 \%$ of respondents not having an internet connection of any kind at home. Even though this was a very small sam- ple size and care should be taken when drawing conclusions, it can be noted that this is in line with a national study that identified a low level of internet access in this population (Rowe and Struthers, 2009). In addition, even though some students were able to access the internet off campus, some highlighted what they felt was a significant financial barrier to more regular access.

Some respondents reported that they were not adequately prepared for the assignment, suggesting that a workshop would have been beneficial. Ramanau and Geng (2009) also found that adequate training of students is essential to the success of projects that make use of social software, like wikis. Competence in the use of emerging technologies is therefore essential in any attempt to integrate social media into teaching practice. Therefore, educators who wish to explore new technologies in the classroom must first provide support and training.

This study found that although a wiki could be used by students to create content as part of a learning activity, they found it difficult to work effectively in their groups. These findings were unexpected in the sense that the researcher had anticipated the students having difficulty with the technology, rather than with groupwork. It was clear from the respondents that the groupwork component of the assignment was for them, the most challenging aspect of all. These findings suggest that while South African healthcare educators should consider integrating technology into their courses, we must understand that using technology does not release us from the fact that sound pedagogy must underlie all curricular design choices.

\section{LIMITATIONS}

Since this survey was carried out in one university physiotherapy department with a small number of participants $(\mathrm{N}=37)$, the results cannot be generalised to broader contexts. However, these results may still have some value for educators in similar contexts who are interested in exploring wiki-based projects in their own fields. 


\section{CONCLUSION AND RECOMMENDATIONS}

Even though this group of students generally believed that they were able to produce relevant content that could be used as a learning resource, they highlighted several challenges with the process. The main difficulty they faced was a poor understanding of effective groupwork, which prevented them from collaborating in the way that a wiki facilitates. The use of feedback and peer review within the wiki was well received by the students, who reported that, together with the fact that the wiki was public, encouraged them to conduct more research than they would usually have done.

In conclusion, the introduction of new teaching and learning tools, like wikis, into the traditional classroom has the potential to enhance teaching and learning practice, but it must be tempered with care and deliberation. If educators are considering the use of social software like wikis, we must ensure that students are well-prepared and supported throughout the process. The use of online tools for collaborative groupwork must be based on a sound pedagogical motivation, and any implementation of technology should seek to enhance, rather than drive, the learning experience.

\section{REFERENCES}

Augar N, Raitman R, Zhou W 2004 Teaching and learning online with wikis. In Atkinson R, McBeath C, Jonas-Dwyer D, Phillips R (eds), Beyond the comfort zone: Proceedings of the 21st ASCILITE Conference 95-104. Perth. Available at http://www.ascilite.org.au/conferences/perth04/ procs/augar.html. Accessed 14 January, 2011

Bennett S, Maton K, Kervin L 2008 The "digital natives" debate: A critical review of the evidence. British Journal of Educational Technology 39:775-786

Biggs J 2003 Teaching for quality learning at university: What the student does, 2nd edn. Open University Press

Boulos, M. N. K., Maramba, I., \& Wheeler, S. (2006). Wikis, blogs and podcasts: a new generation of Web-based tools for virtual collaborative clinical practice and education. BMC medical education $6(41)$
Czerniewicz L, Brown C 2005 Access to ICT for teaching and learning: From single artefact to inter-related resources. International Journal of Education and Development Using Information and Communication Technology 1:42-56

Duffy P, Bruns A 2006 The use of blogs, wikis and RSS in education: A conversation of possibilities. Learning and Teaching Conference 31-38

Game A, Metcalfe A 2009 Dialogue and team teaching. Higher Education Research and Development 28:45-57

Gannon-leary P, Fontainha E 2007 Communities of practice and virtual learning communities: benefits, barriers and success factors. eLearning Papers 5:1-14

Garrison DR, Anderson T 2003) E-learning in the 21st Century. Routledge-Falmer, Abingdon, UK and New York

Jones P 2007 When a wiki is the way: Exploring the use of a wiki in a constructively aligned learning design. Ascilite conference proceedings, Singapore 460-467

Lundin RW 2008 Teaching with Wikis: Toward a Networked Pedagogy. Computers and Composition 25:432-448

Magennis S, Farrell A 2005 Teaching and Learning Activities: Expanding the Repertoire to Support Student Learning. In O’Neill G, Moore S, McMullin B (eds). Emerging Issues in the Practice of University Learning and Teaching, Dublin, All Ireland Society for Higher Education (AISHE). Available at: http://www.aishe.org/readings/2005-1/. Accessed 08 November, 2010

Mak B, Coniam D 2008 Using wikis to enhance and develop writing skills among secondary school students in Hong Kong. System 36:437-455

Mcgarr O 2009 A review of podcasting in higher education: Its influence on the traditional lecture. Australasian Journal of Educational Technology 25:309-321

Partlow, K. M., \& Gibbs, W. J. (2003). Indicators of Constructivist Principles in Internet-Based Courses. Journal of Computing in Higher Education 14:68-97

Prenksy M 2001a Digital natives, digital immigrants. On the Horizon 9:1-6

Ramanau R, Geng F 2009 Researching the use of Wiki's to facilitate group work. Procedia - Social and Behavioral Sciences 1:2620-2626
Rowe M, Struthers P 2009 The use of information and communication technology by South African physiotherapy students. South African Journal of Physiotherapy 65:32-37

Sharma P, Hannafin M 2005 Learner perceptions of scaffolding in supporting critical thinking. Journal of Computing in Higher Education 17:17-42

Shea P, Bidjerano T 2009 Community of inquiry as a theoretical framework to foster "epistemic engagement" and "cognitive presence" in online education. Computers \& Education 52:543-553

Stahl G, Hesse F 2006 Social practices of computer-supported collaborative learning. International Journal of Computer-Supported Collaborative Learning 1:409-412)

Trena M 2006 Challenge or Connect? Dialogue in Online Learning Environments. Journal of Computing in Higher Education 18:3-29

University of the Western Cape 2009 Graduate Attribute policy document.

Vygotsky LS 1978 Mind in society: The development of higher psychological processes. Harvard university press, Cambridge

Wenger E 1998 Communities of practice: Learning, meaning, and identity. Cambridge University Press, New York

\section{DECLARATIONS OF INTEREST}

The author reports that they have no declaration of interest. 